\title{
Blood transfusion needs among obstetric patients in a tertiary care hospital: a prospective observational study
}

\author{
Renuka*, Shridevi A. S., Gayathri L. Patil
}

Department of Obstetrics and Gynecology, SSIMS and RC Davangere, Karnataka, India

Received: 23 September 2019

Accepted: 01 October 2019

\section{*Correspondence:}

Dr. Renuka,

E-mail: renukas12@gmail.com

Copyright: (C) the author(s), publisher and licensee Medip Academy. This is an open-access article distributed under the terms of the Creative Commons Attribution Non-Commercial License, which permits unrestricted non-commercial use, distribution, and reproduction in any medium, provided the original work is properly cited.

\begin{abstract}
Background: Pregnancy possess a special challenge as immune responses in pregnant and non-pregnant states are different. The objectives of this study were to analyze the various indications for blood and blood component transfusion in obstetric patients. To study the prevalence and indications for blood transfusion among obstetric patients. To evaluate the various risk factors among these women. To study the role of antenatal visits in patients requiring blood transfusion

Methods: A prospective observational study will be undertaken over a period of one year from July 2018 to June 2019 in Department of Obstetrics and Gynecology at SSIMS and RC, Davangere. This study was conducted on pregnant women and immediate postpartum patients (up to 7 days after delivery) admitted in Department of Obstetrics and Gynecology and requiring blood and blood component therapy. Statistical analysis will be performed using Chi square test and Student's t test.

Results: During study period out of 5486 patients 543 patients required blood transfusion. The incidence of blood transfusion is $9.89 \%$. The indications for blood and blood product transfusion observed in our study were anemia, obstetric hemorrhage, thrombocytopenia, disseminated intravascular coagulopathy, ruptured ectopic, incomplete abortion, complete abortion and hydatidiform mole. Anemia in pregnancy was the most common indication and was observed in 217 cases (39.96\%) followed by postpartum hemorrhage, which was seen in 117 cases $(21.54 \%)$. The incidence of transfusion reactions was $5.34 \%$ in our study.

Conclusions: A proper knowledge of blood and blood product transfusion is needed to make it available for people who are actually in need and also to decrease the economic burden. Regular Antenatal checkups should be given more importance in order to maximize the hemoglobin level at the time of delivery and to screen out the high-risk patients. Active management of the third stage of labor is required to minimize the blood loss. Anemia followed by obstetric hemorrhage still persists to be a major cause for blood and blood product transfusion.
\end{abstract}

Keywords: Blood transfusion, Component therapy, Transfusion reactions

\section{INTRODUCTION}

Pregnancy possess a special challenge as immune responses in pregnant and non-pregnant states are different. In developing countries obstetric complications are the leading indication for blood transfusion. ${ }^{1}$ Blood transfusion is an integral part of patient management in obstetrics and gynecology. Blood transfusion facility is the backbone of this branch of medicine. ${ }^{2}$ Moreover obstetric condition associated with the need for blood transfusion are associated with considerable morbidity and mortality, if not properly managed. Blood transfusion is recognized as one of the eight essential components of the comprehensive emergency obstetric care module, which has been designed to reduce maternal mortality rates. ${ }^{3}$ Normally, blood loss during the birth is well tolerated because of changes during pregnancy. Obstetric transfusions tend to be urgent, unpredictable and occur in 
otherwise healthy women. ${ }^{3}$ Hemorrhage continues to be the leading cause of maternal mortality worldwide, accounting for $31 \%$ in Asia and $13 \%$ in developed countries. ${ }^{1}$

An obstetric hemorrhage may occur before or after delivery, but more than $80 \%$ of the cases occur postpartum, responsible for $25 \%$ of the estimated $3,58,000$ maternal death each year. ${ }^{3}$ One more common indication for blood transfusion in women is anemia. The prevalence of which is highest in India, with half of the global maternal deaths due to anaemia. ${ }^{4}$ Anaemia is one of the most common nutritional deficiency disorders affecting the pregnant women; the prevalence in developed countries is $14 \%$, in developing countries $51 \%$, and in India, it varies from $65 \%$ to $75 \%$. Anemia is the second most common cause of maternal death in India and contributes to about $80 \%$ of the maternal deaths. Anaemia is also an established risk factor for intrauterine growth retardation, leading on to poor neonatal health and perinatal death. ${ }^{5}$

Various conditions which require blood transfusion in obstetrics are bleeding in first trimester (abortion, ectopic and molar pregnancy), antepartum hemorrhage, postpartum hemorrhage, severe anemia, $\mathrm{PIH}$, thrombocytopenia, DIC. The need for transfusion can be reduced by preventing/treating anemia and blood loss, however there are limitations for prevention and blood transfusion becomes essential. Blood transfusion should be done when benefits are likely to out weight the risks. ${ }^{6}$ Access to a safe and sufficient blood supply can help prevent maternal deaths. Blood transfusion may be a lifesaving procedure but it is not without risk. The incidence of transfusion reactions is 4 in 100 transfusion for non-hemolytic reactions to 1 in 40,000 transfusion for hemolytic reactions. The complication for blood transfusion could be allergic reactions, acute immune hemolytic reaction, delayed hemolytic reaction, risk of transmission of infections, diseases (HIV, Hepatitis B and C). ${ }^{7}$ A pre-planned multidisciplananry protocol yields the best result in management. This study was undertaken in our institute with the objective to ascertain the indications requiring blood transfusion during pregnancy, intrapartum and immediate postpartum period and also to know the type of blood and blood products used.

\section{METHODS}

A prospective observational study was undertaken over a period of one year from July 2018 to June 2019 in the Department of Obstetrics and Gynecology at SSIMS and RC, Davangere. This study was conducted on pregnant patients and immediate postpartum patients (up to 7 days after delivery) admitted in Department of Obstetrics and Gynecology and requiring blood and blood component therapy. Informed consent will be taken, history will be taken, and recruited patients will have a detailed general physical examination, systemic and obstetric examination.

\section{Inclusion criteria}

- All pregnant patients irrespective of the gestational age and site of pregnancy who received blood transfusion for any obstetric cause (abortion, ectopic pregnancy, molar pregnancy, antepartum hemorrhage or anemia)

- $\quad$ Patients in immediate postpartum period (within 7 days of delivery) requiring blood transfusion.

\section{Exclusion criteria}

- Women requiring blood transfusion after 7 days of delivery

- Women with congenital bleeding disorder.

Due consent is taken from ethical committee of hospital. All woman who were transfused with PCV, whole blood, platelets, coagulation factors, fresh frozen plasma are included in this study. The incidence of blood transfusion, indications and adverse reactions of transfusions were noted.

\section{Statistical analysis}

Data was collected in a preformed data sheet. Data was analyzed using SPSS version 21 Statistical analysis will be performed using chi square test and students t test and results are analyzed.

\section{RESULTS}

During the study there were 3480 deliveries, out of which 1032 cesarean section. There were 222 abortions including medical termination of pregnancies. Total 543 patients $(9.89 \%)$ required blood and component transfusion.

\section{Table 1: General information about obstetric admissions during study period.}

\begin{tabular}{|l|l|}
\hline General information & Numbers \\
\hline No of obstetric admissions & 5486 \\
\hline Total no of deliveries & 3480 \\
\hline No of cesarean section & 1032 \\
\hline No of medical termination of pregnancy & 124 \\
\hline No of spontaneous abortion & 98 \\
\hline $\begin{array}{l}\text { No of patients requiring blood } \\
\text { transfusion }\end{array}$ & 543 \\
\hline
\end{tabular}

Out of 5486 patients 543 required blood transfusions i.e $9.89 \%$ of all obstetric patients had blood transfusion in our hospital during study period (Table 1 ).

Commonest age group among study patients is 21-30 years $(70.16 \%)$. Teenage pregnancy constituted less than $10 \%$ of cases. Multiparous patients constituted 317 $(58.37 \%)$ of obstetric patients. Majority of women who required transfusion were among 31-40 weeks of 
gestational age $(71.45 \%)$. Women who delivered by cesarean section $(58.56 \%)$ required more blood transfusion than woman who delivered vaginally $(41.43 \%)$ (Table 2).

Table 2: Sociodemographic characteristics of obstetric patients.

\begin{tabular}{|c|c|}
\hline Characteristics & No. $(\%)$ \\
\hline \multicolumn{2}{|l|}{ Age(years) } \\
\hline$<20$ & $59(10.8)$ \\
\hline $21-30$ & $381(70.16)$ \\
\hline $31-40$ & $97(17.86)$ \\
\hline$>40$ & $6(1.10)$ \\
\hline \multicolumn{2}{|l|}{ Parity } \\
\hline Primigravida & $226(41.62)$ \\
\hline Multigravida & $317(58.37)$ \\
\hline \multicolumn{2}{|c|}{ Gestational age (weeks) } \\
\hline$<10$ & $43(7.91)$ \\
\hline $11-20$ & $57(10.49)$ \\
\hline $21-30$ & $51(9.39)$ \\
\hline $31-40$ & $388(71.45)$ \\
\hline$>41$ & $4(0.73)$ \\
\hline \multicolumn{2}{|l|}{ Type of pregnancy } \\
\hline Ectopic & $27(4.97)$ \\
\hline \multicolumn{2}{|l|}{ Abortion } \\
\hline Incomplete abortion & $9(1.65)$ \\
\hline Complete abortion & $4(0.73)$ \\
\hline Molar & $8(1.47)$ \\
\hline \multicolumn{2}{|c|}{ Intrauterine pregnancy } \\
\hline Singleton & $427(78.63)$ \\
\hline Twins & $68(12.52)$ \\
\hline \multicolumn{2}{|l|}{ Mode of delivery } \\
\hline Vaginal & $128(23.57)$ \\
\hline Operative vaginal & $97(17.86)$ \\
\hline Cesarean delivery & $318(58.56)$ \\
\hline
\end{tabular}

Table 3: Booking status of study patients requiring blood transfusion.

\begin{tabular}{|ll|}
\hline Cases & No. $(n=543)$ \\
\hline Booked & $221(40.69 \%)$ \\
\hline Unbooked & $322(59.30 \%)$ \\
\hline
\end{tabular}

Among 543 patients requiring blood transfusion, $40.69 \%$ cases were booked in our hospital, $59.30 \%$ were unbooked cases. Among booked case $78 \%$ patients had less than 3 antenatal visits and $22 \%$ patients had more than 3 antenatal visits (Table 3 ).

In our study, severe anemia either during pregnancy or during postpartum period was the most common indication $(39.96 \%)$ for transfusion. Postpartum hemorrhage $(21.54 \%)$, placenta Previa (12.33\%), DIC (9.76) and ectopic pregnancy $(3.68 \%)$ were other common indications. Less common indications were abortions, vesicular mole, thrombocytopenia, medical disorders like liver disease, renal disease etc. (Table 4).
Table 4: Indications for transfusion.

\begin{tabular}{|lll|}
\hline Indications & No. $(\mathbf{n = 3 4 2})$ & $\%$ \\
\hline Postpartum hemorrhage & 117 & 21.54 \\
\hline Abruptio placenta & 24 & 4.41 \\
\hline Placenta previa & 67 & 12.33 \\
\hline Abortions & 13 & 2.39 \\
\hline $\begin{array}{l}\text { Ectopic pregnancy } \\
\text { Vesicular mole }\end{array}$ & 20 & 3.68 \\
\hline $\begin{array}{l}\text { Severe anemia during } \\
\text { pregnancy/postpartum } \\
\text { anemia }\end{array}$ & 8 & 1.47 \\
\hline DIC & 217 & 39.96 \\
\hline Thrombocytopenia & 53 & 9.76 \\
\hline Others & 15 & 2.76 \\
\hline
\end{tabular}

Table 5: Total blood and blood products transfused.

\begin{tabular}{|l|l|}
\hline $\begin{array}{l}\text { Types of blood and } \\
\text { components }\end{array}$ & $\begin{array}{l}\text { Number of units } \\
\text { transfused }(\mathrm{n}=574)\end{array}$ \\
\hline Packed cell volume & $354(61.67 \%)$ \\
\hline Whole blood & $43(7.49 \%)$ \\
\hline Platelets & $107(18.64 \%)$ \\
\hline Fresh frozen plasma & $66(11.49 \%)$ \\
\hline Cryoprecipitate & $4(0.69 \%)$ \\
\hline
\end{tabular}

In our study $354(61.67 \%)$ received packed cells, 107 $(18.64 \%)$ received platelets, $66(11.49 \%)$ received fresh frozen plasma, $43(7.49 \%)$ received whole blood and 4 $(0.69 \%)$ received cryoprecipitate (Table 5).

Table 6: Distribution of cases as per blood unit requirement.

\begin{tabular}{|l|l|}
\hline $\begin{array}{l}\text { No. of blood units } \\
\text { transfused per case }\end{array}$ & $\begin{array}{l}\text { Total no of units } \\
\text { transfused }(\mathbf{n}=574))\end{array}$ \\
\hline 1 & $115(21.17)$ \\
\hline 2 & $217(39.96 \%)$ \\
\hline 3 & $135(24.86 \%)$ \\
\hline 4 and more & $76(13.99 \%)$ \\
\hline
\end{tabular}

As shown in Table 6, it is observed that $39.96 \%$ patients required 2 units of blood transfusion. Only $21.17 \%$ patients required 1 unit of blood transfusion. Four or more units of blood transfusion were required in $13.99 \%$ patients (Table 6).

Table 7: Transfusion reactions.

\begin{tabular}{|lll|}
\hline Transfusion reactions & No. & $\%$ \\
\hline Urticarial rash & 13 & 2.39 \\
\hline Chills & 9 & 1.65 \\
\hline TRALI & 7 & 1.28 \\
\hline None & 514 & 94.65 \\
\hline
\end{tabular}

In the present study, $29(5.34 \%)$ out of 543 woman had a transfusion reaction while $514(94.65 \%)$ had none. Out of 29 woman $7(1.2 \%)$ had a major transfusion reaction in the form of transfusion reaction in the form of transfusion 
related acute lung injury, while remaining had minor transfusion reactions such as urticarial rash and chills (Table 7).

\section{DISCUSSION}

Pregnancy although a physiological state, can turn pathological, suddenly and unexpectedly, if not cared for. Acute blood loss can occur in first half of pregnancy due to complications like abortions, ectopic pregnancy rupture and vesicular mole.

In later half of pregnancy, there can be hemorrhage due to low lying placenta or accidental hemorrhage. During pregnancy if iron supplementation is not taken properly it can aggravate the physiological anemia of pregnancy. Anemia is an important indirect cause of maternal mortality in developing countries.

During labor, women may develop third stage hemorrhage or other complications resulting in severe blood loss and sudden deterioration in general condition of mother. Immediate and rapid replacement of sufficient and safe blood becomes essential to save the life of mother. On one side maternal morbidity and mortality depends on availability of blood and blood products which can cause infections, allergic reactions or antibody production in the mother which can have major impact on the present or future pregnancies. ${ }^{8}$

Blood is an expensive and scarce resource. So, a proper knowledge for blood and blood product transfusion is needed to avoid irrational use of blood and blood products transfusion and thus making it available for people who are actually in need and also to decrease the economic burden.

At our centre we conducted a prospective observational study to analyse the incidence, indications and complications of blood and blood product transfusion among obstetric patients. Our study showed transfusion rate of $9.89 \%$ for all obstetric patients. Most common age group for transfusion is between 21-30 years $(0.16 \%)$. This is similar to study done by Chowdhary et al where the transfusion rate was $9.23 \%$ and common age group was from $21-30$ years $(76.58 \%){ }^{9}$

Majority of transfusions were done for patients of gestational age $31-40$ weeks $(71.45 \%)$. Similar observation was made by Chawla $\mathrm{S}$ et al. ${ }^{10}$ In their study $23(71.8 \%)$ women were in 31-40 weeks of pregnancy. The rate of transfusion is more in women who delivered by caesarean section $(58.56 \%)$ than vaginal deliveries $(41.43 \%)$. Study by Butwick et al has shown that caesarean delivery is an important risk factor for transfusion. ${ }^{11}$

Among obstetric patients, who received blood transfusion, (46\%) were booked and (54\%) were un- booked. This is in accordance to observation made by Chowdhary F et al. ${ }^{9}$

In our study, multiparous patients constituted $58.37 \%$ of the total obstetric patients received transfusion. In the present study, it was observed that severe anaemia, either during pregnancy or during postpartum period was the most common indication $(39.96 \%)$ for transfusion. Postpartum hemorrhage $(21.54 \%)$, placenta previa (12.33\%), DIC (9.76) and ectopic pregnancy (3.68\%) were other common indications. Less common indications were abortions, vesicular mole and thrombocytopenia etc. The results of our study are comparable to study done by Bengal VB et al. ${ }^{12}$

In the present study $61.67 \%$ patients were transfused PCV, $18.64 \%$ patients received platelets, $11.49 \%$ received fresh frozen plasma. Very small percentages of patients were transfused with whole blood (7.49\%) and cryoprecipitate transfusion. Patel VP et al in their study titled Study of role of blood transfusion in obstetric emergencies reported that $80 \%$ patients were transfused with PCV only and $20 \%$ patients received combination of blood and blood products like FFP, PRC, and Cryoprecipitate. ${ }^{13}$

In the present study, 29 out of 543 women $(5.34 \%)$ had a transfusion reaction while $514(94.65 \%)$ had none. A study conducted by Deshpande $\mathrm{M}$ et al reported that 9 out of 204 women $(4.41 \%)$ had a transfusion reaction, among which 1.47 had urticarial rash, $1.47 \%$ had chills and $1.47 \%$ had transfusion related acute lung injury. ${ }^{14}$

Nigam et al, in their study titled blood transfusion in obstetrics reported that transfusion of blood and blood components is a common practice in obstetric wards but it is not without risk. The incidence of transfusion reactions varies from 4 in every hundred transfusions for non-hemolytic reactions to one in every 40,000 for hemolytic transfusion reactions. ${ }^{7}$

In developing countries 2 main causes of maternal mortality and morbidity regarding blood transfusion in obstetrics are;

- Anaemia of pregnancy

- Massive obstetric haemorrhage.

The haemoglobin trigger for giving blood transfusion in pregnancy is less than $7 \mathrm{~g} / \mathrm{dl}$. Anaemia still persists to be major cause for blood and blood product transfusion.

Obstetric haemorrhage is defined as any blood loss occurring in the peripartum period may be revealed or concealed, that is likely to endanger life. Massive and life threatening haemorrhage occurs in $3-5 \%$ and $0.1 \%$ of deliveries respectively and blood product transfusion is required in $0.3-1 \% .{ }^{10}$ 
Obstetric haemorrhage is an emergency situation and cannot always be predicted or avoided. Active management of third stage of labour should be implemented strictly. A well-functioning blood bank is very essential to provide blood and blood products in the time of such emergencies. Packed red blood cells should be used in obstetric emergencies rather than whole blood for transfusion as whole blood leads to increased plasma volume, thus causing circulatory overload. Fresh frozen plasma is very useful in the management of accidental haemorrhage and cases with massive blood loss as it prevents or controls dreadful complications like DIC. It also helps in preventing other complications like acute renal failure and shock.

The decision of blood transfusion should be made both clinical and haematological grounds. Transfusion is almost always indicated when haemoglobin is less than 7 $\mathrm{gm} / \mathrm{dl} .{ }^{15}$ Most of the patients transfused were unbooked cases. These results show the inadequate antenatal care of woman, poor nutrition and lack of awareness of importance of hematinic therapy.

An early involvement of consultant obstetrician, anaesthetist, haematologist and blood bank is essential. Blood transfusion though a lifesaving procedure, still possess a vital threat of transfusion reactions and various other transfusion related morbidities. According to world health organisation, the four cornerstones of a safe and effective blood donor services are a rational system, volunteer donations, blood testing and avoidance of unnecessary transfusions. ${ }^{16}$

\section{CONCLUSION}

Blood transfusion is lifesaving essential component of obstetric care. Acute obstetric blood loss is usually unpredictable and sudden. Identifying the risk factors for hemorrhage in antenatal period and anticipating bleeding is essential in managing obstetric hemorrhage.

The decision to transfuse should be time taken to maintain adequate tissue oxygenation in the cases of acute hemorrhage. Regular antenatal check-ups should be given more importance to maximize the hemoglobin level and to screen out the high-risk patients. Education of staff and awareness about reporting the transfusion reactions is a key step in improving the safety of blood transfusions and preventing transfusion reactions.

Funding: No funding sources Conflict of interest: None declared

Ethical approval: The study was approved by the Institutional Ethics Committee

\section{REFERENCES}

1. Schantz-Dunn J, Nour NM. The use of blood in obstetrics and gynecology in the developing World. Rev Obstet Gynecol. 2011;4(2):86-91.
2. Anjali K, Varsha K, Sulabha J, Anuja B, Bhavana K, Savita S. Blood transfusion in obstetrics and gynaecology: a retrospective analysis. Panacea J Med Sci. 2015;5(3):109-12.

3. McLintock C, James AH. Obstetric hemorrhage. J Thromb Haemost. 2011;9:1441-51.

4. Chhabra S, Namgyal A. Rationale use of blood and its components in obstetric-gynecological practice. J Mahatma Gandhi Inst Med Sci. 2014;19:93-9.

5. Suryanarayana R, Chandrappa M, Santhuram AN, Prathima S, Sheela SR. Prospective study on prevalence of anemia of pregnant women and its outcome: a community-based study. J Family Med Prim Care. 2017;6(4):739-43.

6. The clinical use of blood. Blood transfusion safety. World health organization, Geneva 2002. Available at: http://www.who.int/bloodsafety/BTS_ ResolutionsAdopted.pdf.

7. Nigam A, Prakash A, Saxena P. Blood transfusion in obstetrics. Kathmandu Univ Med J. 2013;11(44):355-9.

8. Royal College of Obstetricians and Gynaecologists. Blood transfusion in obstetrics. Green-top Guideline No. 47. London (UK): Royal College of Obstetricians and Gynaecologists; 2007. Available at: https://www.rcog.org.uk/en/guidelines-researchservices/ guidelines/gtg47/.

9. Chowdhury F, Akhter S, Islam A, Rayen J, Begum $\mathrm{N}$, Begum F. Evaluation of blood transfusion practices in obstetrics and gynecology in a tertiary hospital in Bangladesh. J Bangladesh College Physicians Surgeons. 2016;34:9-14.

10. Chawla S, Bal MH, Vardhan BS, Jose CT, Sahoo I. Blood transfusion practices in obstetrics: our experience. J Obstet Gynaecol India. 2018;68(3):204-7.

11. Butwick AJ, Aleshi P, Fontaine M. Retrospective analysis of transfusion outcomes in pregnant patients at a tertiary obstetric center. Int J Obst Anesth. 2009;18:302-8.

12. Bangal VB, Gavhane SP, Aher KH, Bhavsar DK, Verma PR, Gagare SD. Pattern of utilization of blood and blood components in obstetrics at tertiary care hospital. Int J Reprod Contracept Obstet Gynecol. 2017;6(10):4671-6.

13. Patel VP, Patel RV, Shah PT, Patel CK. Study of role of blood transfusion in obstetric emergencies. Int J Reprod Contracept Obstet Gynaecol. 2014;3:10025.

14. Madhushree D, Metgud MC, Patil K. Retrospective analysis of all patients undergoing blood transfusion in obstetrics at a Tertiary Care Hospital, Belgaum: A cross-sectional study. Indian J Health Sci Biomed Res. 2018;11(2):116.

15. British Committee for Standards in Haematology, Blood Transfusion Task Force. Guidelines for the clinical use of red cell transfusions. Br J Haematol. 2001;113:24-31.

16. World Health Organization (WHO). Essential health technologies. Blood transfusion safety, 2011. 
Available at: http://www.who.int/ bloodsafety/en/Blood_Transfusion_Safety.pdf. Accessed on $14^{\text {th }}$ June 2011.
Cite this article as: Renuka, Shridevi AS, Patil GL. Blood transfusion needs among obstetric patients in a tertiary care hospital: a prospective observational study. Int J Reprod Contracept Obstet Gynecol 2019;8:4244-9. 